\title{
EFFECT OF LAMINA THICKNESS ON FLEXURAL PERFORMANCE AND CREEP BEHAVIOR OF DOUGLAS FIR GLUED LAMINATED TIMBER BEAM
}

\author{
Tawich Pulngern, Kasan Chanto, Waraluk Pansuwan \\ King Mongkut's University of Technology Thonburi \\ Thailand \\ Woraparn Pattaraumpornsak \\ Deco Enterprises Co., Ltd. \\ Thailand \\ (Received November 2019)
}

\begin{abstract}
This research presents the effects of lamina thickness on flexural and creep performances of glulam timber. Flexural test results indicated that nonlinear load-displacement curve could be defined as both exponential and power functions. Lamina thickness was not affected to nonlinear curve, especially at initial linear relationship. Slightly different of $2.92 \%$ for nonlinear function parameters was obtained. For flexural creep test due to three levels of sustained load for 1,000 hours, only secondary creep stage behaviors without delamination were observed for all glulam timbers while average relative creep was 1.66. Effect of lamina thickness was also not found for creep performance. Finally, creep models have been developed including Bailey-Norton, adjusted Pickel, simplified Pickel, and Dorn models and found that Bailey-Norton and the adjusted Pickel models gave a good correlation with experiment and were the suitable models which could be used to predict long-term flexural creep behavior for various stress levels.
\end{abstract}

KEYWORDS: Glued laminated timber, lamina thickness, flexural behavior, creep characteristics.

\section{INTRODUCTION}

Timber is the oldest well-known and widely used in various fields, e.g. as a structural material and building's finishes due to its strength and aesthetics (Ramage et al. 2017). However, it is not suitable for the long span construction with high bending moment value such as bridges because of the limited natural geometry of the wood. Then, the glued laminated timber (glulam) was introduced in an early period to solve the issues. Consequently, a lot of long span bridges and 
buildings were built with glulam with an advantage of reducing the $\mathrm{CO}_{2}$ emission (Gutkowski and Williamson 1983, Lehringer and Gabriel 2014, O’Born 2018). However, structural glulam can be manufactured by using various lamina thicknesses. For example, a section with the depth of $0.40 \mathrm{~m}$. could be assembled by gluing 4 layers of $0.10 \mathrm{~m}$. lamina thickness or 2 layers of $0.20 \mathrm{~m}$. lamina thickness. Therefore, some researchers focused on effect of lamina thickness. In 2004, Shmulsky (2004) reported that the compressive strength and stiffness were not affected by the lamina thickness. But, an increasing of lamina number or decreasing the lamina thickness could be decreased the variation of yield strength and modulus of elasticity by over $50 \%$. This was due to the fact that woods which were selected to make glulam member was typically structural grade and higher lamina number trend to reduce the defect of wood.

Besides the study on the static flexural behavior of glulam beam, the long term mechanical behavior was also considered which may result the reduction of structural stiffness or rupture (Hayman 1981). Creep is one of the long term mechanical behaviors which may disastrous affect the structure. Some researchers carried out the creep behavior of wood such as Holzer et al. (1989) who published the review article on the creep behavior including the effects of environment. Moreover, changes in moisture and temperature also affected the creep behavior of wood (Bodig and Jayne 1982, Dillard et al. 1989). Later Barrett (1982) also concluded that moisture and temperature gave less effect on the creep behavior in case of glued laminated timber. This was due to the fact that overall thickness of the element and the glued layer in laminate timber could be reduced the environmental effect. Moreover, according to the design recommendation given by Humphries and Schniewind (1982), the designed creep behavior should be within the secondary creep stage or steady state since the tertiary creep stage may lead to rupture of the member. Thus, the creep models which have been introduced mostly are the convergence function covering only the secondary stage. The research work of Dillard and Hiel (1985) also stated that the power law or power function were the most suitable for long term behavior prediction of polymer and timber.

From the literature review reported previously, only the effect of lamina thickness on compression and tension were conducted. However, the effect of lamina thickness on the flexural performance and flexural creep behavior has been extremely important since the glulam timber beam can be manufactured with various lamina thicknesses but the literature review indicated that no researches have been conducted yet. Therefore, this research focuses on the investigation of the flexural performance and creep behavior of glulam beams which have been manufactured with difference lamina thickness. The experimental and analytical results can be used to proof the manufacturing process and may be used to predict the flexural behavior and long term creep behavior of glulam timber beam.

\section{MATERIAL AND METHODS}

\section{Sample preparation}

This investigation focuses on the effect of lamina thickness on the flexural performance and flexural creep behaviors of glulam timber beam. Douglas fir (Pseudotsuga menziesii) which supplied by Deco Enterprises Co., Ltd. (Bangkok, Thailand) was used. The glulam specimens were manufactured by using polyurethane (commercial brand of COSMO PU-160.110 of Weiss Chemie + Technik) as a wood adhesive. The adhesive was uniformly applied on the surface of the dressed wood and pressed the specimen with the pressure of $0.015 \mathrm{~N} \cdot \mathrm{m}^{-2}$ for $90 \mathrm{~min}$ according to the adhesive specification. Four groups of specimen were prepared which are 1-layer timber (solid timber), 2-layers glulam, 3-layers glulam, and 4-layers glulam with 3 specimens for each group. 
The groups of specimens were abbreviated name as ST, GL2, GL3, and GL4, respectively. The dimension and the span-to-depth ratio of the testing specimen was designed to be conformed ASTM D198 (2014). Based on the standard, the dimension of a rectangular prismatic beam is $90 \times 90 \times 1,440 \mathrm{~mm}$ (width $\times$ breadth $\times$ length) as shown in Fig. 1 and the recommended span-depth ratios are 11 to 15 . Thus, the prepared specimen has a span-depth ration of 15 and the overhanging at supports with overhanging-length-depth of 1 . Moreover, a lamina thickness depends on the lamina thickness. The lamina thickness for ST, GL2, GL3, and GL4 are $90 \mathrm{~mm}$, $45 \mathrm{~mm}, 30 \mathrm{~mm}$, and $22.5 \mathrm{~mm}$ respectively.

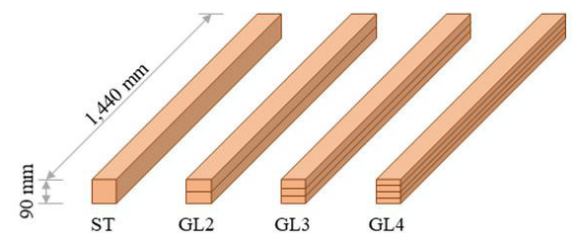

Fig. 1: Schematic diagram of samples.

\section{Static flexural test}

The flexural behavior of Douglas-fir glulam was conducted in accordance with ASTM D143 (2014) and ASTM D198 (2014). Fig. 2 illustrates the experimental setup for static four-point bending (Song and Hong 2018) test for Douglas fir glulam beam specimen.

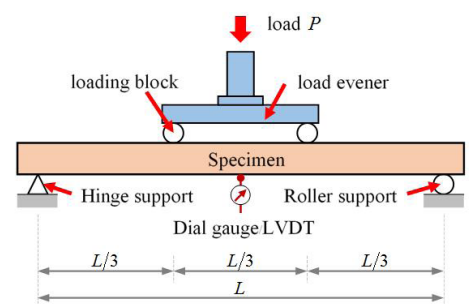

Fig. 2: Static four-point bending test of timber beam.

The specimen was installed on two hinge-roller supports as simply supported beam with the span length of $L$ or $1,350 \mathrm{~mm}$ for this research $(L / 15)$. The loading block and the load evener were set and loaded by the universal testing machine (UTM: Shimadzu UHF1000kNX, capacity of $1,000 \mathrm{kN}$ ) at the position of $L / 3$ from each support with a loading speed of $2.5 \mathrm{~mm} \cdot \mathrm{min}^{-1}$ until the specimen was ruptured. The flexural behavior of the Douglas fir glulam beam has been recorded and determined including load-displacement relationship, modulus of elasticity (MOE), stress at proportional limit $\left(f_{p}\right)$, and modulus of rupture (MOR).

\section{Flexural creep test}

The flexural creep test of Douglas-fir glulam was carried out based on the four-point bending test and in accordance with ASTM D198 (2014). The schematic diagram of the flexural creep testing frame is shown in Fig. 3. The testing frame in accordance with the previous author's research (Pulngern et al. 2010) was designed and modified to carry the sustained load of the testing specimens and concrete loading weight without any significant displacement which may affect the experiment. The steel pulleys were used to magnify the loading weight up to 10 times 
for force applying to the specimen through the rigid loading evener and loading blocks. There level of applied loads for the flexural creep tests were varied from 25\%, 40\%, and 55\% of the average ultimate flexural strength obtained from the static flexural test as specified in ASTM D6815 (2009). The displacement or deflection was recorded by using dial gauge positioned at the mid span of the testing specimen. The creep displacements at mid span of the specimen under sustained load were recorded which reflected the displacement in minute intervals $(1,2,5,15$ and $30 \mathrm{~min})$ and afterward in intervals $(1,2,5,20,24,48,72,120,168,240,360,504,720,840$, 960 , and 1,000 hours). The instantaneous displacement $(1 \mathrm{~min})$ and the creep displacement were considered.

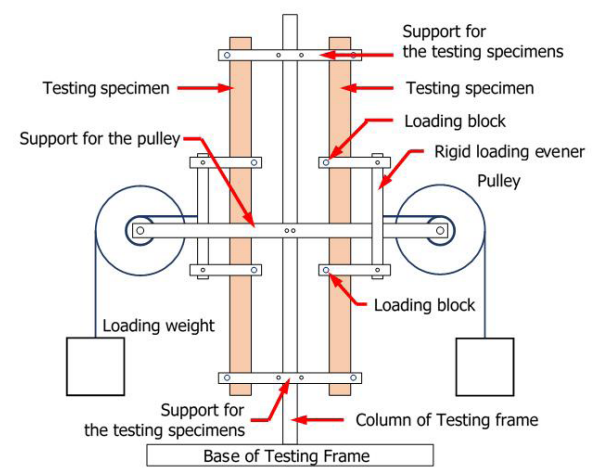

Fig. 3: Testing frame and setup for flexural creep test.

\section{RESULTS AND DISCUSSION}

\section{Flexural behavior and models}

Fig. 4 represents the nonlinear load-displacement curves for the flexural behavior of all Douglas fir glulam specimens with different lamina thickness. The obtained load-displacement curves also interpreted that all tested specimens were a brittle material with relatively short plastic range. The failure mode for all tested specimens was simple tension and cross-grain tension without any sign of delamination.

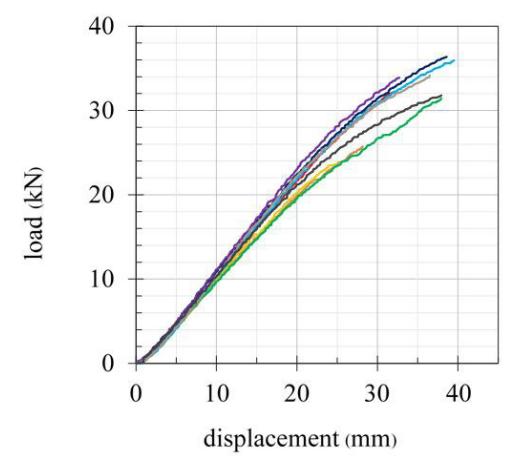

Fig. 4: Load-deflection curves of Douglas-fir glued laminated timber beam. 
The obtained results also showed that there were no significant differences between groups of specimen with different lamina thickness and could be concluded that the lamina thickness had no effect on the flexural performance of the Douglas fir glulam specimen. The average modulus of elasticity, stress at proportional limit and modulus of rupture were $7.768 \mathrm{MPa}, 26.31 \mathrm{MPa}$ and 47.39 MPa, respectively. Comparing to the previous research (Chen et al. 2017), the tested specimens gave almost the same strength with only $1.40 \%$ difference. The average static flexural properties were used to consider the loading weight of the upcoming flexural creep test.

In order to confirm effect of lamina thickness, nonlinear load-displacement relationship of glulam beam was considered. This is due to the fact that glue-laminated timber is nonlinear material, Hooke's law may not be applicable. By considering nonlinear material of natural wood and wood-plastic based materials, literature review indicated that nonlinear stress-strain relation in form of polynomial ( $\mathrm{Li}$ et al. 2009, Macbain and Saadeghvaziri 1999), exponential (Naghipour et al. 2011, Pulngern et al. 2013), and power functions (Solano-Carrillo 2009, Lee 2002) were typically presented. For this research, the nonlinear load-displacement relationship was also developed by using the least squares nonlinear curve fitting of exponential and power functions as follow:

$$
\begin{aligned}
& P=A\left(1-e^{-B \delta}\right) \\
& P=k \delta^{1 / n}
\end{aligned}
$$

where: $\quad P$ is applied load $(\mathrm{kN}), \delta$ is displacement at mid span $(\mathrm{mm}), A, B, k$, and $n$ are constants related with the mechanical behavior of the material.

The summary of fitted parameters of nonlinear load-displacement of timbers with various lamina thicknesses are represented in Tab. 1. According to the fitted parameters of all timber beams, first parameter of two nonlinear models is almost constant while the second parameter gave slightly deviation within $2.92 \%$. The obtained results indicated that there had no effect of lamina thickness on nonlinear load-displacement relation of glue-laminated timber. As presented previously, both flexural properties and load-displacement relationship of Douglas-fir glulam beam did not depend on lamina thickness and effect of lamina thickness during the structural design phase can be neglected.

Tab. 1: Summary of fitted parameters for the flexural model.

\begin{tabular}{|c|c|c|c|c|c|c|}
\hline \multirow{2}{*}{ Specimen } & \multicolumn{3}{|c|}{ Exponential function } & \multicolumn{3}{c|}{ Power function } \\
\cline { 2 - 7 } & $A$ & $B$ & Deviation & $k$ & $n$ & Deviation \\
\hline GL2 & 132.5 & 0.0086 & $1.60 \%$ & 1.27 & 1.0896 & $0.95 \%$ \\
\hline GL3 & 132.5 & 0.0086 & $2.08 \%$ & 1.27 & 1.0851 & $1.91 \%$ \\
\hline GL4 & 132.5 & 0.0084 & $2.92 \%$ & 1.27 & 1.0696 & $1.88 \%$ \\
\hline
\end{tabular}

\section{Flexural creep models}

The flexural creep test had been operated at the close room with controlling temperature (average of $29.4^{\circ} \mathrm{C}$ ) and humidity (average $85 \%$ ) during the test. Fig. 5 represents the flexural creep response of the Douglas fir glulam beam specimen with different lamina thickness and stress level. By varying the three stress levels of 25\%, 40\%, and 55\% for the duration of 1,000 hours, the tested flexural creep responses showed that the difference of lamina thickness had no significant effect on the flexural creep behavior of the glulam specimen. All of the tested specimens presented the secondary creep behavior or phase of constant creep rate. The primary 
creep or the transient creep stage lasted averagely 81 hours after loading which was higher than the steel-wood composite element with approximately 20 hours (Zhao et al. 2019). The result indicated that the Douglas fir glulam beam could be used as a construction material without the consideration of the effect of lamina thickness. Moreover, delamination between layers were not found even the glued layer was located at the center of the section which the highest value of internal horizontal shear stress always occurs.

However, the creep displacement should be considered at the design phase. The relative creep, which is defined as the ration between the displacement due to creep at 1,000 hours, $\delta_{f}$ and the instantaneous displacement $(1 \mathrm{~min}),. \delta_{i}$ or can be written as this following equation:

$$
\text { Relative creep }=\delta_{f} / \delta_{i}
$$

The maximum relative creep ratio and its average value were 1.66 and 1.42 respectively. This means that the displacement at secondary creep stage, which is the convergence creep displacement, may lead to 1.66 times the instantaneous displacement which should be taken into account during the structural design process. Comparing to the relative creep results concluded by the recent researches (Gowda et al. 1996, Shen and Gupta 1997), the relative creep for Douglas fir lumber with moisture content of $10 \%$ and $11 \%$ was less than 1.40 which slightly lower than the average relative creep obtained from this research because the tested specimens had higher moisture content of $14 \%$. It was raised from the fact that the higher moisture content yield higher relative creep (Pulngern et al 2010).

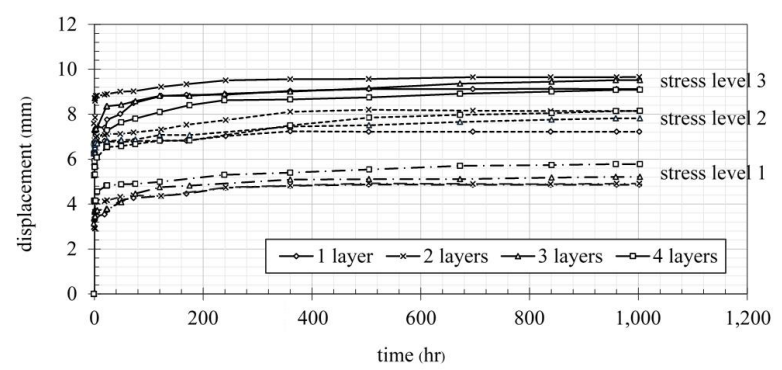

Fig. 5: Creep response, displacement-time curves of Douglas-fir glued laminated timber beam.

The stress-time-temperature dependent behavior of materials, $\delta_{c}$ can be considered by using an empirical creep models (Holzer et al. 1989, Boresi and Schnidt 2002) which are formed by the combination of the Kelvin-Voigt model and the Maxwell model (Mase 1970, Chen and Zhu 2019). Since the temperature has been controlled during the experiment, the power function given by Bailey-Norton and the exponential function given by Dorn were raised. The mathematical expression of Bailey-Norton's power law model (Bailey 1935, Norton 1929) and Dorn model (Dorn 1962), which can be well fitted with the tested results, are stated as following equations:

$$
\begin{aligned}
& \delta_{c}=a \sigma^{b} t^{m} \\
& \delta_{c}=a e^{b \sigma} t^{m}
\end{aligned}
$$

Where $a, b$, and $m$ are constants that can be obtained by using the least square nonlinear curve fitting technique, $\sigma$ is stress ( $\mathrm{MPa}$ ), and $t$ is time (hour). The combined stress-timetemperature creep behavior of material can also be predicted by using hyperbolic function such as Pickel model (Pickel et al. 1971) which can be expressed as follows: 


$$
\begin{aligned}
& \delta_{c}=a e^{(-A / T)} \sinh (b \sigma) t^{m} \\
& \delta_{c}=a e^{(-A / T)}[\sinh (b \sigma)]^{k} t^{m}
\end{aligned}
$$

where: $a, b, k, m$, and $A$ are constants, and $T$ is a temperature variable.

Since the temperature is constant, the exponential term becomes constant. Thus, both of the equations can be rearranged and stated as equations (8) and (9) which are the stress-time dependent creep models called simplified Pickel model and adjusted Pickel model respectively.

$$
\begin{aligned}
& \delta_{c}=a \sinh (b \sigma) t^{m} \\
& \delta_{c}=a[\sinh (b \sigma)]^{k} t^{m}
\end{aligned}
$$

These constants or the creep parameters were determined from the tested results as shown in Tab. 2. Fig. 6a-d showed comparison between the experimental results and the predicted creep behavior of Bailey-Norton, adjusted Pickel, simplified Pickel, and Dorn model correspondingly. The results reflected that these creep models correlated with the experimental result with the $R^{2}$ value of $0.907-0.943$. Specifically, the Bailey-Norton's power law model and the adjusted Pickel model performed the best fitting with the $R^{2}$ value of 0.943 . Mathematically, these two models have almost the same expression. Since the $b$ value of the adjusted Pickel model is relatively small, with the Taylor expressions of the hyperbolic sine function, the adjusted Pickel model gives approximately same value as Bailey-Norton. Therefore, the Bailey-Norton and the adjusted Pickel model yielded the best correlation with the result for the tested Douglas fir glulam beam and could be used to predict the long-term flexural creep behavior of the specimens which could be represented by:

$$
\begin{aligned}
& \delta_{c}=0.624 \sigma^{0.768} t^{0.031} \\
& \delta_{c}=1,439.6[\sinh (0.0004 \sigma)]^{0.768} t^{0.031}
\end{aligned}
$$

\begin{tabular}{|c|c|c|c|}
\hline Creep model & Parameter & Value of parameter & $R^{2}$ \\
\hline \multirow{3}{*}{ Bailey-Norton } & $a$ & 0.624 & \multirow{3}{*}{0.943} \\
\hline & $b$ & 0.768 & \\
\hline & $m$ & 0.031 & \\
\hline \multirow{4}{*}{ Adjusted Pickel } & $a$ & $1,439.6$ & \multirow{4}{*}{0.943} \\
\hline & $b$ & 0.00004 & \\
\hline & $k$ & 0.768 & \\
\hline & $m$ & 0.031 & \\
\hline \multirow{3}{*}{ Simplified Pickel } & $a$ & $2,836.5$ & \multirow{3}{*}{0.907} \\
\hline & $b$ & 0.00011 & \\
\hline & $m$ & 0.030 & \\
\hline \multirow{3}{*}{ Dorn } & $a$ & 2.692 & \multirow{3}{*}{0.921} \\
\hline & $b$ & 0.040 & \\
\hline & $m$ & 0.031 & \\
\hline
\end{tabular}

Tab. 2: Summary of fitted parameters for the creep model. 


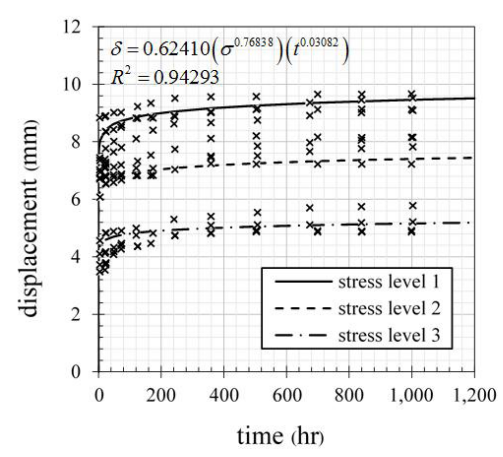

(a) Bailey-Norton model

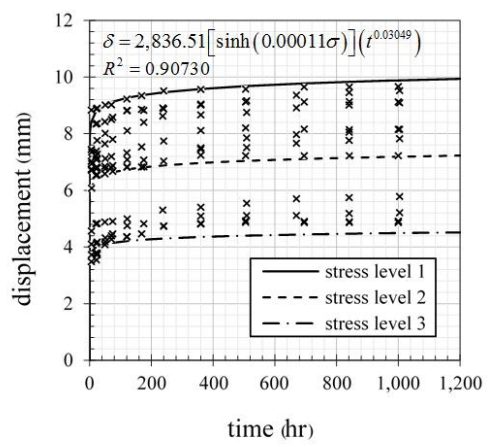

(c) Simplified Pickel model

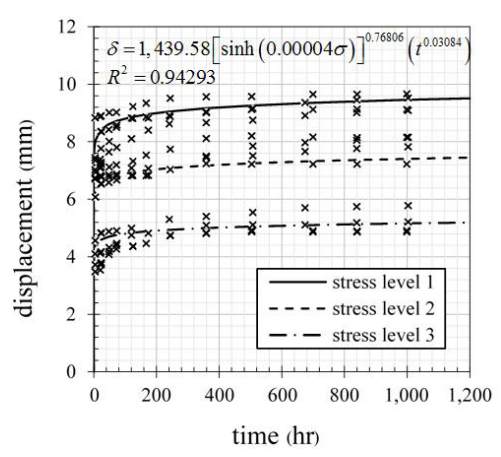

(b) Adjusted Pickel model

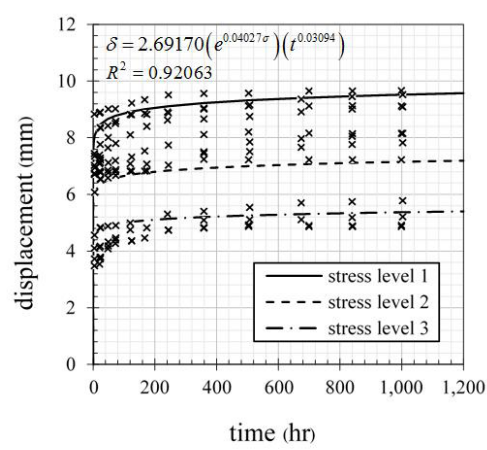

(d) Dorn model

Fig. 6: Predicted flexural creep model.

\section{CONCLUSIONS}

In this work, the effect of lamina thickness on flexural performance and creep behavior of Douglas fir glulam beams was conducted. These following results have been concluded: (1) The lamina thickness was not significantly affected on flexural performance of Douglas fir glulam beam. The exponential and power functions for nonlinear load-displacement curves are also proposed. All test specimens were failed in tension mode at extreme bottom fiber of the wood section without delamination behavior. (2) The lamina thickness does not affect the flexural creep behavior of the glulam beam. Within sustained loads of 1,000 hours, all specimens presented only secondary creep stage behavior without delamination. The obtained average relative creep of all glulam beams with various lamina thicknesses was 1.66. (3) The combined time-stress dependencies flexural creep models for Douglas fir glulam beam have been developed including Bailey-Norton power model, adjusted Pickel model, simplified Pickel model, and Dorn model. Bailey-Norton and the adjusted Pickel model give a good correlation with the experimental results with the satisfied $R^{2}$ value of 0.943 and there were most suitable models to predict the long-term flexural creep behavior. 


\section{ACKNOWLEDGMENTS}

The authors gratefully acknowledge financial supports by the Institutional Research Capability Development Grant from the Thailand Research Fund (TRF), King Mongkut's University of Technology Thonburi, and sincerely thank Deco Enterprises Co., Ltd.

\section{REFERENCES}

1. ASTM D143, 2014: Standard test methods for small clear specimens of timber.

2. ASTM D198, 2014: Standard test methods of static tests of lumber in structural sizes.

3. ASTM D6815, 2009: Standard specification for evaluation of duration of load and creep effects of wood and wood-based products.

4. Bailey, R.W., 1935: The utilization of creep test data in engineering design. Proceedings of the Institution of Mechanical Engineers 131(1): 131-349.

5. Barrett, J.D., 1982: Effects of loading time on design. In: Structural uses of wood in adverse environments (ed: Meyer, R.W., Kellog, R.M.). Society of Wood Science and Technology. Van Nostrand Reinhold Company. New York, Pp 301-316.

6. Bodig, J., 1982: Moisture effects on structural use of wood. In: Structural uses of wood in adverse environments (ed: Meyer, R.W., Kellog, R.M.). Society of Wood Science and Technology. Van Nostrand Reinhold Company, New York, Pp 53-75.

7. Boresi, A.P., Schmidt, R.J., 2002: Advanced Mechanic of Material, 6th ed. Pp 624-655, John Willey \& Son, New York, Pp 624-655.

8. Chen, D., Zhang, W., Wu, Y.S., Jin, Z., Zhang, Q.W., 2019: Investigation on the mechanical properties of open-hole spruce and Douglas fir. Wood Research 64(1): 155-164.

9. Chen, Y., Zhu, J., 2019: Study on bending characteristics of fast growing Eucalyptus bookcase shelves by using Burgers model. Wood Research 64(1): 137-144.

10. Dillard, D.A., Gramoll, K.C., Brinson, H.F., 1989: The implications of the fiber truss concept for creep properties of laminated composites. Composite Structures 11(2): 85-100.

11. Dillard, D.A., Hiel, C., 1985: Singularity problems of the power law for modeling creep compliance. The 1985 SEM Spring Conference on Experimental Mechanics. Society for Experimental Mechanics, Las Vegas Pp 142-148.

12. Dorn, J.E., 1962: Progress in understanding high-temperature creep, H. W. Gillett Memorial Lecture. American Society for Testing Materials. Philadelphia, 22 pp.

13. Gowda, S., Kortesmaa, M., Ranta-Maunus, A., 1996: Long term creep tests on timber beams in heated and non-heated environments. VTT Publication 278. Espoo, 35 pp.

14. Gutkowski, R.M., Williamson, T.G., 1983: Timber bridges: State of the art. Journal of Structural Engineering 109(9): 2175-2191.

15. Hayman, B., 1981: Creep buckling - A general view of the phenomena, Creep in Structures. International Union of Theoretical and Applied Mechanics, 3 ${ }^{\text {rd }}$. Springer, Berlin.16. Holzer, Pp 289-307.

16. Holzer, S.M., Loferski, J.R., Dillard, D.A., 1989: A review of creep in wood: Concepts relevant to develop long-term behavior predictions for wood structures. Wood and Fiber Science 21(4): 376-392.

17. Humphries, M., Schniewind, A.P., 1982: Behavior of wood columns under cyclic relative humidity. Wood Science 15(1): 44-48. 
18. Lee, K., 2002: Large deflection of cantilever beam of non-linear elastic material under combined Loading. International Journal of Non-linear Mechanics 37(3): 439-443.

19. Lehringer, C., Gabriel, J., 2014: Review of recent research activities on one-component PUR-adhesives for engineered wood products. In: Materials and Joints in Timber Structures (ed. Aicher S, Reinhardt H-W, and Garrecht H). RILEM Bookseries, Vol. 9, Springer, Dordrecht. Pp 405-420.

20. Li, Y.F., Xie, Y.M., Tsai, M.J., 2009: Enhancement of the flexural performance of retrofitted wood beams using CFRP composite sheets. Construction and Building Materials 23(1): 411-422.

21. Macbain, K., Saadeghvaziri, M.A., 1999: Analytical modeling of the mechanical properties of recycled plastics. Journal of Materials Engineering and Performance 8(3): 339-346.

22. Mase, G.E., 1970: Continuum mechanics. Schaum's Outlines. McGraw-Hill. New York. Pp 196-216.

23. Naghipour, M., Nematzadeh, M., Yahyazadeh, Q. 2011: Analytical and experimental study on flexural performance of WPC-FRP beams. Construction and Building Materials 25(2): 829-837.

24. Norton, F.H., 1929: The creep of steel at high temperature. McGraw-Hill, New York. Pp 67-70.

25. O’Born, R., 2018: Life cycle assessment of large scale timber bridges: A case study from the world's longest timber bridge design in Norway. Transportation Research Part D: Transport and Environment 59: 301-312.

26. Pickel, T.W., Sidebottom, O.M., Boresi, A.P., 1971: Evaluation of creep law and flow criteria for two metals subjected to stepped load and temperature changes. Experimental Mechanics 11(5): 202-209.

27. Pulngern, T., Chimkrai, A., Rosarpitak, V., Sombatsompop, N., 2013: Analytical, numerical and experimental investigations on flexural strengthening for wood/PVC composite members using flat bar strips. Construction and Building Materials 41: 545-556.

28. Pulngern, T., Chucheepsakul, S., Padyenchean, C., Rosapitak, V., Prapuit, W., Chaochanchaikul, K., Sombatsompop, N., 2010: Effects of cross-section design and loading direction on the creep and fatigue properties of wood/PVC composite beams. Journal of Vinyl \& Additive technology 16(1): 42-49.

29. Ramage, M.H., Burridge, H., Busse-Wicher, M., Fereday, G., Reynolds, T., Shah, D.U., Wu, G., Yu, L., Fleming, P., Densley-Tingley, D., Allwood, J., Dupree, P., Linden, P.F., Scherman, O., 2017: The wood from the trees: The use of timber in construction. Renewable and Sustainable Energy Reviews 68 Part 1: 333-359.

30. Shen, Y., Gupta, R., 1997: Evaluation of creep behavior of lumber. Forest Products Journal 47: 89-96.

31. Shmulsky, R., 2004: Effect of lamina thickness on parallel-to-grain strength in small Douglas fir samples. Journal of Bridge Engineering 9(3): 308-309.

32. Solano-Carrillo, E., 2009: Semi-exact solutions for large deflections of cantilever beams of non-linear elastic behavior. International Journal of Non-Linear Mechanics 44(2): 253-256.

33. Song, Y.J., Hong, S.I., 2018: Performance evaluation of the bending strength of larch crosslaminated timber. Wood Research 63(1): 105-116.

34. Zhao, W., Yang, B., Zhou, J., 2019: Axial compressive creep behavior of a square steel tube/ bamboo plywood composite column with binding bars. Wood Research 64(2): 223-236. 
*Tawich Pulngern, Kasan Chanto

King Mongkut's University of Technology Thonburi

Faculty of Engineering

Department of Civil Engineering

in 6 Pracha-Uthit Road, Thung Khru

IOI 4 O BANGKOK

Thailand

*Corresponding author: tawich.pul@kmutt.ac.th

Waraluk Pansuwan

King Mongkut's University of Technology Thonburi

School of Architecture and Design

49 Thian Thale 25, Bang Khun Thian

IOI5O BANGKOK

Thailand

Woraparn Pattaraumpornsak

Deco Enterprises Co., Ltd.

873 Sukhumvit, Phra Khanon

IO260 BANGKOK

Thailand 
